\title{
Over-the-scope clip placement and endosponge insertion for prevention of pancreatic enzyme- induced duodenal damage after large duodenal endoscopic resection
}

A 61-year-old woman with familial adenomatous polyposis and previous proctocolectomy was admitted for resection of duodenal adenomas (Spigelman classification IV). A formation of two confluent adenomas with low grade dysplasia, measuring $3.5 \times 2.5 \mathrm{~cm}$ with a central depression (laterally spreading tumor mixed type; Paris IIa $+\mathrm{c}$ ), was found at the lower duodenal knee (D2/D3) ( $\bullet$ Fig. 1 a).

After an attempt of endoscopic mucosal resection, endoscopic submucosal dissection was performed using hydroxyethyl starch with indigo carmine blue and a $1.5 \mathrm{~mm}$ FlushKnife (straight type; Fujifilm, Tokyo, Japan) ( Fig.1 b). After complete resection, the denuded area had a size of $4 \times 3 \mathrm{~cm}$ ( $\nabla$ Fig. $1 \mathrm{c}$ ). Two atraumatic, $17.5 \mathrm{~mm}$, over-the-scope clips ,type a (OTSC; Ovesco, Tuebingen, Germany) were placed to reduce the size of the unprotected area; standard hemoclips were also placed ( $\bullet$ Fig. $1 \mathrm{~d}$ ). However, the flow of pancreatic and biliary secretions was seen to slow. Therefore, in order to protect the mucosa from the digestive enzymes, additional duodenal vacuum sponge implantation was performed.

The vacuum sponge, $2.5 \mathrm{~cm}$ long and $1.8 \mathrm{~cm}$ wide (Endo-Vac; Braun, Melsungen, Germany), was introduced via an overtube (US Endoscopy, Mentor, Ohio, USA), and then transported to the duodenum using a rat tooth forceps ( $\bullet$ Fig. 1 e). The tube was externalized via the nose, and suction of $-125 \mathrm{mmHg}$ was started. Pantoprazole $40 \mathrm{mg}$ was administered three times a day to reduce gastric secretion. Follow-up endoscopy on postoperative Day 4 showed the sponge still in place. After sponge retrieval, no signs of perforation or aberrant wound healing were present ( $\bullet$ Fig.1f). The clinical course was uneventful, and laboratory results returned to normal values.

Widespread endoscopic resection of duodenal tumors is technically feasible but is associated with complications, such as de- layed bleeding and perforation, in up to $30 \%$ of cases $[1,2]$. Vacuum sponge insertion is already used in endoscopic treatment for complicated abdominal surgery $[3,4]$. We promote its use as prophylactic treatment in addition to OTSC placement after resection of large duodenal adenomas, in order to prevent perforation or bleeding due to damage caused by pancreatic and biliary juices.

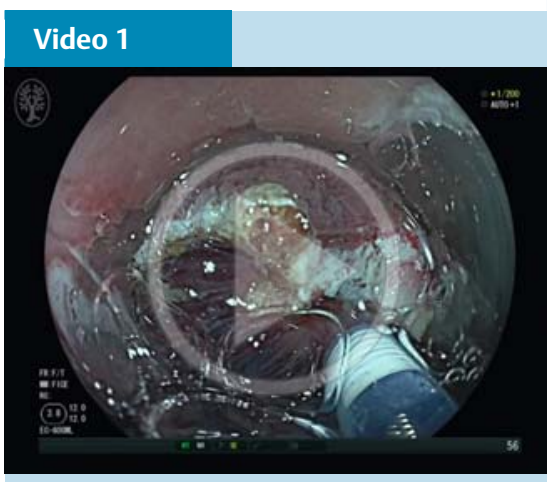

Over-the-scope clip placement and endosponge insertion for the protection of the duodenal mucosa following widespread endoscopic resection. Steps shown include attempted endoscopic mucosal resection, endoscopic submucosal dissection, clip placement (including over-the-scope clips), and endosponge insertion and retrieval. Follow-up endoscopy was performed on postoperative Day 4.
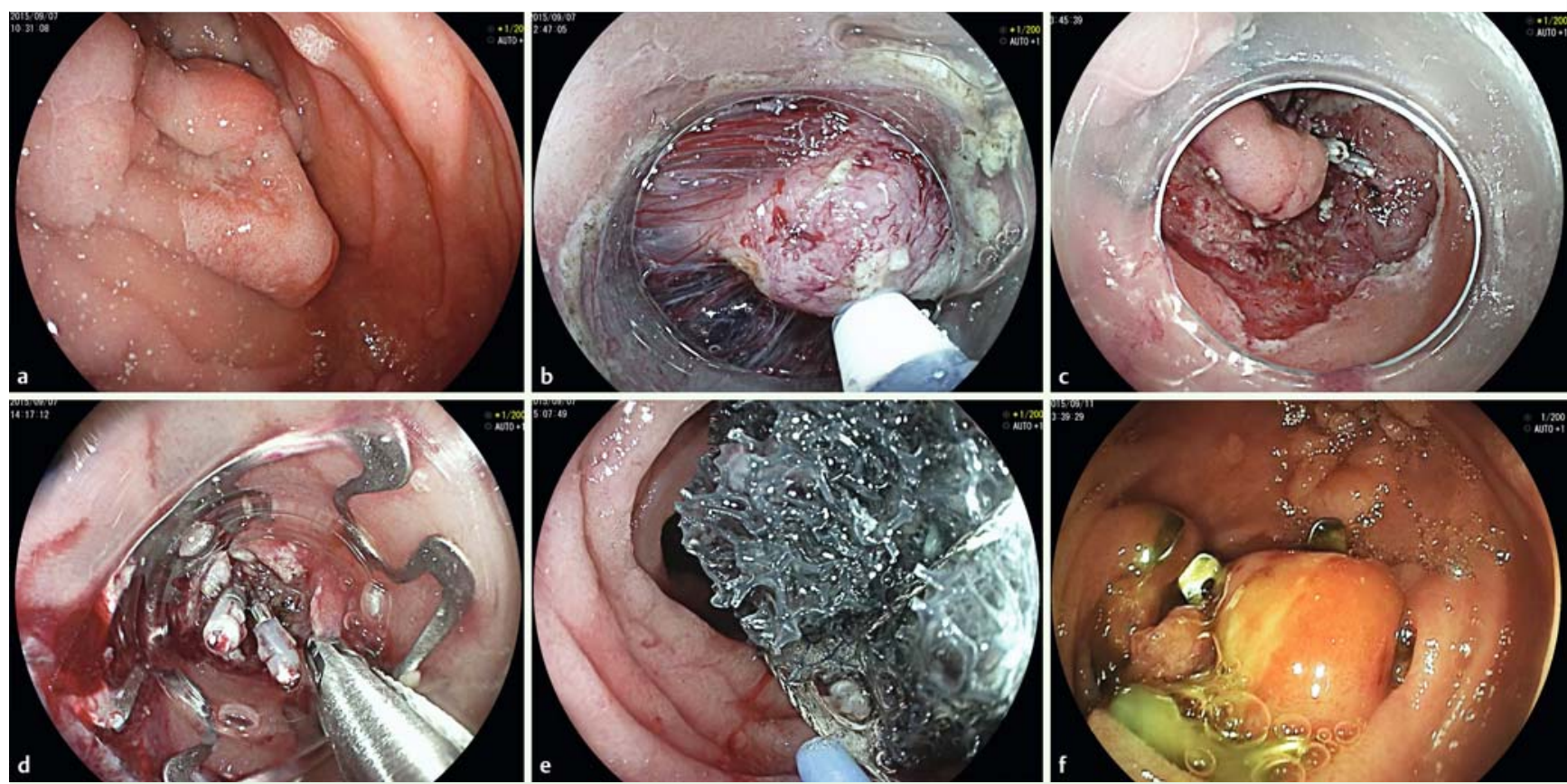

Fig. 1 Over-the-scope clip placement and endosponge insertion for the protection of the remaining duodenal muscular layer following endoscopic resection (EMR/ESD). a Adenomas with low grade dysplasia in the lower part of the duodenum (D2/D3). b ESD of highly vascularized duodenal adenoma using a $1.5 \mathrm{~mm}$ FlushKnife (straight type; Fujifilm, Tokyo, Japan). $\mathbf{c}$ The denuded area after duodenal ESD. $\mathbf{d}$ Clips and over-the-scope clips were placed to reduce the size of the unprotected area. e Transnasal-transgastric placement of a duodenal endosponge. f Follow-up endoscopy on postoperative Day 4. 


\section{Endoscopy_UCTN_Code_TTT_1AO_2AN}

\section{Competing interests: None}

\section{Juergen Hochberger ${ }^{1,2}$, Edris Wedi ${ }^{2,3}$,} Irina Tchoumak ${ }^{2}$, Carlo Jung ${ }^{2,3}$

${ }^{1}$ Department of Gastroenterology, Vivantes Klinikum im Friedrichshain, Academic Teaching Hospital of Charité University, Berlin, Germany

2 Department of Gastroenterology, Nouvel Hôpital Civil, Strasbourg University Hospitals, Strasbourg, France

${ }^{3}$ Department of Gastroenterology and Gastrointestinal Oncology, University Medical Center Göttingen, Göttingen, Germany

\section{References}

1 Fanning SB, Bourke MJ, Williams SJ et al. Giant laterally spreading tumors of the duodenum: endoscopic resection outcomes, limitations, and caveats. Gastrointest Endosc 2012; 75: 805-812

2 Jung JH, Choi KD, Ahn JY et al. Endoscopic submucosal dissection for sessile, nonampullary duodenal adenomas. Endoscopy 2013; 45: 133-135

3 Wedemeyer J, Brangewitz M, Kubicka S. Management of major postsurgical gastroesophageal intrathoracic leaks with an endoscopic vacuum-assisted closure system. Gastrointest Endosc 2010; 71: $382-386$

4 Weidenhagen R, Gruetzner KU, Wiecken T et al. Endoscopic vacuum-assisted closure of anastomotic leakage following anterior resection of the rectum: a new method. Surg Endosc 2008; 22: $1818-1825$

\section{Bibliography}

Dol http://dx.doi.org/

10.1055/s-0042-122419

Endoscopy 2016; 48: E401-E402

(c) Georg Thieme Verlag KG

Stuttgart · New York

ISSN 0013-726X

\section{Corresponding author}

\section{Juergen Hochberger MD, PhD}

Department of Gastroenterology Vivantes Health Network

Friedrichshain Hospital

Academic Teaching Hospital of Charité University Landsberger Allee 49

D-10249 Berlin

\section{Germany}

Fax: +49-30-130232053

juehochber@mac.com 